\title{
Aging and obesity are associated with undiagnosed hypertension in a cohort of males in the Central Province of Sri Lanka: a cross-sectional descriptive study
}

N. W. I. A. Jayawardana ${ }^{1}$, W. A. T. A. Jayalath², W. M. T. Madhujith³, U. Ralapanawa², R. S. Jayasekera4, S. A. S. B. Alagiyawanna ${ }^{2}$ A. M. K. R. Bandara ${ }^{5}$ and N. S. Kalupahana ${ }^{6^{*}}$

\begin{abstract}
Background: Lifestyle factors associated with hypertension $(H T)$ in South Asian populations are relatively unknown. The objective of the current study was to investigate the prevalence rates of undiagnosed $H T$ and factors associated with it in a cohort of males from the Central Province of Sri Lanka.

Methods: The study group consisted of 2462 males (mean age 31 years, range: 16-72 years) who underwent a routine medical examination at the National Transport Medical Institute, Kandy, Sri Lanka. Participants with previously diagnosed heart disease, diabetes, hypertension or other chronic illnesses were excluded from this study. Dietary and other lifestyle factors were studied using validated self-administered questionnaires. Body Mass Index (BMI) cut-off values for Asians were used to categorize the subjects according to weight status. The association of individual dietary and lifestyle patterns with HT was assessed by fitting into binary logistic regression models.

Results: The mean systolic (SBP) and diastolic blood pressures (DBP) of the individuals were $125.9 \mathrm{mmHg}$ and 80 . $5 \mathrm{mmHg}$, respectively. The prevalence rate of undiagnosed HT was 31.7\%. Both SBP and DBP showed significant positive correlations with age, weight, BMI and waist circumference. After adjusting for potential confounders, HT was associated with older age $(p=0.001)$ and increased weight status $(p<0.001)$ with trends of association for level of education $(p=0.058$ ). Level of income, alcohol consumption, sleeping hours, smoking, physical activity level, ethnic difference, consumption of fruits, fish, meat, dairy, sweets or fried snacks were not significantly associated with HT. Obese males were 92.1\% [odds ratio: 1.9 (1.4-2.7)] more likely to be hypertensive compared to normal weight males.

Conclusions: Undiagnosed HT is prevalent at an alarming rate among adult males in the Central Province of Sri Lanka. Its association with age and BMI (weight status) highlights the importance of routine screening for HT as well as interventions targeted at reducing obesity to curb the rise of this modifiable cardiovascular disease risk factor.
\end{abstract}

Keywords: Hypertension, Age, BMl, Obesity, Lifestyle factors, Systolic and diastolic blood pressure, South Asians

\footnotetext{
* Correspondence: skalupahana@pdn.ac.lk

${ }^{6}$ Department of Physiology, Faculty of Medicine, University of Peradeniya,

Peradeniya, Sri Lanka

Full list of author information is available at the end of the article
} 


\section{Background}

An estimated 800 million adults in the world are suffering from hypertension (HT) [1], a cardiovascular disease risk factor which is estimated to account for $6 \%$ of all deaths [2]. The prevelance of HT has also increased steadily over the last two decades [1]. Around $80 \%$ of the burden of hypertension and its complications are observed in low and middle-income countries [3]. Economic development, industrialization, nutrition transition and globalization that lead to a rapidly change in lifestyles could at least in part account for the increasing prevalence of hypertension. More than a quarter of the world's population is already hypertensive and this number is projected to increase up to $29 \%$ by 2025 [4]. However, hypertension can be asymptomatic [5] and many people with hypertension may not get any treatment until the outcomes become serious. The detection and control of HT is thus a major public health challenge. Sri Lanka is a South Asian nation with lower-middle income status. According to the World Health Organization (WHO) non-communicable diseases country profiles, the prevalence of hypertension among Sri Lankans was 39.2\% (41.4\% in males and $37.1 \%$ in females) in year 2008 [6].

While the relationship between lifestyle patterns and hypertension has been extensively studied in western populations, less data is available regarding the risk factors associated with hypertension in South Asia. Since the dietary habits and physical activity patterns of Sri Lankans are different from that of western counterparts [7], it is imperative to find out the exact risk factors for HT in Sri Lanka, so that effective interventions can be tailored to prevent this condition.

To date, the only national study conducted in Sri Lanka by Katulanda et al., has shown that male gender is a significant risk factor for developing hypertension [8]. Thus, the aim of the present study was to determine the underlying lifestyle factors associated with hypertension among a cohort of males in the Central Province of Sri Lanka.

\section{Methods}

\section{Research design and population}

The data for this study were obtained from the baseline assessment of the National Transport Medical Test Cohort, a prospective study being conducted to assess lifestyle factors associated with non-communicable disease risk factors in the Central Province of Sri Lanka. Detailed methods have been previously published [9]. Briefly, the current analysis was a cross-sectional descriptive study in 2462 adult males (age range 16 to 72 years), who presented for a routine medical evaluation at the National Transport Medical Institute, Kandy, Sri Lanka from January 2013 to February 2014. Participants with previously diagnosed heart diseases, diabetes, hypertension or other chronic illnesses were excluded from this study.

\section{Ethics, consent and permissions}

This study was approved by the ethics review committee (Institutional review board) of the Faculty of Medicine, University of Peradeniya, Sri Lanka (2015/EC/13). Informed written consent was obtained from all participants.

\section{Data collection}

\section{Systolic and diastolic blood pressure}

Two readings of systolic and diastolic blood pressure were taken from the right arm of each subject in a sitting position after a 10-min rest using a standard clinical mercury manometer (0125B Accoson Dekamet Mercury Sphygmomanometer, UK). Mean value of the two readings were taken as the BP of the participant. A systolic blood pressure (SBP) of $\geq 140 \mathrm{mmHg}$ or diastolic blood pressure (DBP) of $\geq 90 \mathrm{mmHg}$ were considered as the cut-off level to determine the presence of hypertension [10].

\section{Anthropometric measurements}

WHO guidelines were followed in obtaining height, weight and waist circumference (WC) measures [11]. Height was measured using a stadiometer (Healthweigh ${ }^{\odot}$ Mechanical Physician Scale (RL-MPS), Goldbell Weigh-System, Singapore) to the nearest millimetre. Weight was measured using a digital scale (Healthweigh ${ }^{\circledR}$ Mechanical Physician Scale (RL-MPS), Goldbell Weigh-System, Singapore) to the nearest $100 \mathrm{~g}$. An inelastic measuring tape was used to measure the waist circumference to the nearest millimetre at the midpoint between the lowest palpable rib and the superior border of the iliac crest in the mid axillary line at the end of normal expiration.

The body mass index (BMI) was calculated as weight $(\mathrm{kg}) /$ height $^{2}\left(\mathrm{~m}^{2}\right)$. Weight status was categorized using the BMI cutoff values for Asians as defined by WHO [12]. The weight categories were: underweight (BMI $<18.5 \mathrm{~kg} / \mathrm{m}^{2}$ ), normal weight (BMI $18.5-22.9 \mathrm{~kg} / \mathrm{m}^{2}$ ), overweight $\left(23-27.5 \mathrm{~kg} / \mathrm{m}^{2}\right.$ and obese $\left(>27.5 \mathrm{~kg} / \mathrm{m}^{2}\right)$. $\mathrm{WC} \geq 90 \mathrm{~cm}$ was defined as abdominal obesity [13].

\section{Dietary, physical activity and other lifestyle data}

A validated self-administered food frequency questionnaire was used to collect dietary data reflecting the consumption over the past six months. The short version of the International Physical Activity Questionnaire (IPAQ) was employed to assess the physical activity during one week [14]. Details of the questionnaires have been previously published [9]. Alcohol consumption, smoking and sleep duration were collected using a self-administered questionnaire. Physical activity levels were categorized into low (< 150 min of moderate-intensity physical activity or $75 \mathrm{~min}$ of vigorous-intensity activity per week), 
medium (150-300 min of moderate-intensity activity or 75-150 min of vigorous-intensity physical activity per week) or high (> $300 \mathrm{~min}$ of moderate-intensity physical activity per week) [14-16]. Regarding the smoking score, moderate smokers were defined as a person smoking 1-10 cigarettes per day, while heavy smokers were defined as smoking $>10$ cigarettes per day [17]. When sleep hours were considered, a low sleep score was given to individuals who slept for $<6 \mathrm{~h}$ per day while medium and high scores were given for persons who slept for $6-8 \mathrm{~h}$ per day and $>8 \mathrm{~h}$ per day respectively [18]. Demographic data on age, ethnicity, level of education and household income were collected by interviewer-administrated questionnaires.

\section{Statistical analysis}

Data analysis was performed without imputing for missing values. Mean and Standard Deviation (SD) were calculated for continuous variables while frequencies and percentages were calculated for categorical variables. The mean differences of SBP and DBP between age categories, ethnic groups and educational levels were tested for significance by fitting a ANOVA model for each variable separately and mean separation was done using Duncan's new multiple range test (DNMRT). Correlation between variables was analysed for significance with the Pearson correlation coefficient. Two binary logistic regression models were fitted to assess the associations of individual dietary patterns and other lifestyle patterns with hypertension. In these models, healthy (non-hypertensive) group was used as the reference category and the effect of each variable was tested after adjusting for other confounding variables. Further, in logistic regression analysis, independent variables; alcohol intake, sleeping hours, smoking, consumption of fruits, fish, meat, dairy, sweets and fried snacks were considered as numerical variables and entered into the model as frequency per week; and age group, education level, income level, weight status and ethnicity were entered into the model as categorical variables in model 1 and education level was considered as an ordinal variable in model 2. All analysis was carried out using SAS 9.3 (SAS Institute Inc., Cary, NC) considering a significance level of 0.05 .

\section{Results}

Of the 2462 subjects, 1627 (66.1\%) were less than 35 years old, while 566 (22.9\%), 227 (9.2\%) and 42 (1.7\%) belonged to $35-44,45-54$ and 55 years or above categories respectively. The majority of the sample were Sinhalese (2065-84.1\%), followed by Moors (201-8.2\%) and Tamils (191-7.8\%). Other baseline characteristics of the sample are summarized in Table 1. Eighty-four
Table 1 Baseline characteristics of the study sample

\begin{tabular}{lll}
\hline Characteristic & Mean & $\pm \mathrm{SD}$ \\
\hline Age (years) & 31 & 10.3 \\
Height $(\mathrm{m})$ & 1.6 & 0.1 \\
Weight $(\mathrm{kg})$ & 62.5 & 11.9 \\
Systolic blood pressure $(\mathrm{mm} \mathrm{Hg})$ & 125.9 & 11.2 \\
Diastolic blood pressure $(\mathrm{mm} \mathrm{Hg})$ & 80.5 & 7.3 \\
BMI $\left(\mathrm{kg} \mathrm{m}^{-2}\right)$ & 22.7 & 4.2 \\
WC $(\mathrm{cm})$ & 78.6 & 11.3 \\
\hline
\end{tabular}

SBP Systolic blood pressure, $D B P$ Diastolic blood pressure, $B M I$ body mass index, $S D$ standard deviation, $W C$ waist circumference

percent of the study subjects had an education level of Ordinary Level or above, while $85 \%$ had a monthly income in the range of LKR 13,000 to 50,000 (US $\$ 1 \sim$ LKR 150). The prevalence rate of previously undiagnosed hypertension of the study group was $31.7 \%$. The prevalence rates of overweight and obesity in the sample were $31.8 \%$ and $12.3 \%$, respectively. Moreover, $17.1 \%$ of the subjects were centrally obese.

When the lifestyle patterns were considered, $22.5 \%$ of the study group consumed alcohol and $14.4 \%$ were smokers $(14.2 \%$ of them were moderate smokers and $0.2 \%$ were heavy smokers). While $78.6 \%$ of participants reported having $7-8 \mathrm{~h}$ of sleep per day, $64.5 \%$ of the participants indicated that they engage in $300 \mathrm{~min}$ or more of moderate-intensity physical activity per week. The study group had a relatively low fruit intake with only $14.5 \%$ of participants eating more than 1 fruit per day. Detailed description of the demographics and lifestyle habits of these participants have been recently published elsewhere [9].

To study the different factors associated with HT in this group, first we compared the mean SBP and DBP levels between different groups according to age, ethnicity, education level and physical activity level (Table 2). The mean SBP and DBP showed a significant difference between age groups, with a trend towards increasing blood pressure with aging. No significant difference was observed in mean SBP and DBP among ethnic groups. While participants who had educated up to grade 5 or less had significantly higher mean SBP compared to other educational levels, this was a modest difference with no difference of DBP according to educational status (Table 2). Finally, there was no difference in mean SBP or DBP among the different levels of self-reported physical activity levels.

Next we studied the associations between age, indices of adiposity and lifestyle factors with SBP and DBP. Similar to the findings of increased blood pressure in different age groups, we found a significant positive 
Table 2 Mean systolic and diastolic blood pressures according to age, ethnicity, education level and physical activity level

\begin{tabular}{lll}
\hline Category & $\begin{array}{l}\text { Mean SBP }( \pm \text { SD), } \\
\mathrm{mm} \mathrm{Hg}\end{array}$ & $\begin{array}{l}\text { Mean DBP }( \pm \text { SD), } \\
\mathrm{mm} \mathrm{Hg}\end{array}$ \\
\hline $\begin{array}{l}\text { Age category (years) }(n=2462) \\
<20\end{array}$ & $124.1^{\mathrm{a}}(10.6)$ & $78.9^{\mathrm{a}}(6.9)$ \\
$20-30$ & $124.8^{\mathrm{a}, \mathrm{b}}(10.8)$ & $79.9^{\mathrm{a}, \mathrm{b}}(7.2)$ \\
$31-40$ & $126.0^{\mathrm{b}}(10.8)$ & $80.7^{\mathrm{b}}(7.2)$ \\
$41-50$ & $128.4^{\mathrm{c}}(12.4)$ & $82.4^{\mathrm{c}}(7.3)$ \\
$>50$ & $130.7^{\mathrm{d}}(11.4)$ & $82.9^{\mathrm{c}}(8.5)$ \\
Ethnicity ( $n=2457)$ & & \\
Sinhalese & $125.9^{\mathrm{a}}(11.3)$ & $80.5^{\mathrm{a}}(7.4)$ \\
Tamil & $126.1^{\mathrm{a}}(9.3)$ & $80.8^{\mathrm{a}}(6.1)$ \\
Moor & $126.0^{\mathrm{a}}(12.2)$ & $80.7^{\mathrm{a}}(8.6)$ \\
Education level ( $n=2339)$ & & \\
No education - grade 5 & $131.2^{\mathrm{a}}(11.1)$ & $82.6^{\mathrm{a}}(5.6)$ \\
Grade 6 - grade 11 & $126.1^{\mathrm{b}}(11.8)$ & $80.4^{\mathrm{a}}(7.6)$ \\
Ordinary level passed & $125.9^{\mathrm{b}}(10.8)$ & $80.8^{\mathrm{a}}(7.3)$ \\
Advanced level passed & $125.5^{\mathrm{b}}(11.5)$ & $80.1^{\mathrm{a}}(7.3)$ \\
Graduate/postgraduate & $129.4^{\mathrm{a}, \mathrm{b}}(13.1)$ & $81.7^{\mathrm{a}}(6.8)$ \\
Physical activity level $(n=2462)$ & & $80.3^{\mathrm{a}}(7.6)$ \\
Low & $125.7^{\mathrm{a}}(11.6)$ & $80.2^{\mathrm{a}}(7.3)$ \\
Medium & $125.9^{\mathrm{a}}(10.7)$ & $80.7^{\mathrm{a}}(7.2)$ \\
\hline High & $126.1^{\mathrm{a}}(11.0)$ & \\
\hline
\end{tabular}

a,b,c,d Mean SBP and DBP values with different superscripts in a column within the same category are significantly different $(p<0.05)$

correlation of both SBP and DBP with age (Table 3). Moreover, indices of adiposity (BMI and WC) showed significant positive correlations with both SBP and DBP. In contrast, there were no significant correlations between intensity of physical activities (high, medium, low), sleep or smoking scores with SBP or DBP.

Table 3 Correlation (linear) of systolic and diastolic blood pressure with age, smoking score, sleeping core, physical activity level, BMI, waist circumference and weight

\begin{tabular}{|c|c|c|}
\hline & \multicolumn{2}{|c|}{ Correlation co-efficient $(r)$} \\
\hline & SBP & DBP \\
\hline Age & $0.166^{*}$ & $0.163^{*}$ \\
\hline Smoking score & -0.008 & -0.001 \\
\hline Sleep score & -0.010 & 0.006 \\
\hline BMI & $0.166^{*}$ & $0.192^{*}$ \\
\hline WC & $0.200^{*}$ & $0.216^{*}$ \\
\hline Weight & $0.168^{*}$ & $0.184^{*}$ \\
\hline \multicolumn{3}{|l|}{ Time (minutes) spent on } \\
\hline Low intensity physical activities & -0.033 & -0.024 \\
\hline Moderate intensity physical activities & -0.024 & -0.019 \\
\hline Vigorous intensity physical activities & -0.014 & 0.001 \\
\hline
\end{tabular}

*Significant correlations $(p<0.05)$

$n=2462$
Finally, to investigate whether the aforementioned associations are independent ones, we performed a logistic regression to find the predictors of hypertension. The binary logistic regression analysis results revealed that, only age $(p=0.001)$ and weight status $(p<0.001)$ were significantly and independently associated with hypertension. While level of education $(p=0.058)$ was trending towards significance, ethnicity $(p=0.783)$, physical activity level $(p=0.684)$, income status $(p=0.440)$, level of sleeping hours $(p=0.348)$, smoking $(p=0.936)$, consumption of alcohol $(p=0.522)$, fish $(p=0.647)$, meat $(p=0.298)$, dairy $(p=0.113)$, fruits $(p=0.594)$, sweets $(p=0.989)$ or fried snacks $(p=0.609)$ were not significantly associated with hypertension (Table 4). Since the level of education was trending towards significance when it was treated as categorical variable, we further investigated the effect of education on hypertension treating the education as an ordinal (rank) scale variable and results revealed that neither linear $(p=0.077)$ nor quadratic $(p=0.051)$ term was significant (Table 5).

Table 6 has summarized the prevalence rates of HT among different groups according age, ethnicity and education level. According to age, the undiagnosed hypertension was highest among the eldest age group (age > 50 years) and the prevalence rate of undiagnosed hypertension increased with age. Participants aged $>50$ years were $123 \%$ (OR: 2.23 ; 95\% CI: 1.14 , 4.35) more likely to have hypertension compared to males $<20$ years of age (Table 5). Further, undiagnosed hypertension was highest among overweight and obese males

Table 4 Variables Associated with Hypertension in the Logistic Regression Model 1

\begin{tabular}{lll}
\hline Variable & Chi-Square & $P$ value \\
\hline Age & 18.27 & $0.001^{*}$ \\
Ethnicity & 0.49 & 0.783 \\
\#Level of education & 9.14 & 0.058 \\
Level of smoking & 0.39 & 0.529 \\
Alcohol consumption & 0.41 & 0.522 \\
Physical activity level & 0.17 & 0.684 \\
Level of sleeping & 0.88 & 0.348 \\
Consumption of meat & 1.08 & 0.298 \\
Consumption of fish & 0.21 & 0.647 \\
Consumption of dairy & 2.51 & 0.113 \\
Consumption of fried snacks & 0.26 & 0.609 \\
Consumption of fruits & 0.28 & 0.594 \\
Consumption of sweets & 0.0002 & 0.989 \\
Weight status & 19.84 & $0.000^{*}$ \\
Income status & 3.75 & 0.440 \\
\hline
\end{tabular}

"Level of education entered as a categorical variable; * $p<0.05$ 
Table 5 Odds Ratios of Variables Associated with Hypertension in the Logistic Regression Model 2

\begin{tabular}{llr}
\hline Covariate & Hypertension OR $(95 \% \mathrm{Cl})$ & $P$ value \\
\hline Age & & 0.001 \\
20-30 years Vs. $<20$ years & $0.98(0.56,1.72)$ & \\
31-40 years Vs. $<20$ years & $1.09(0.62,1.91)$ & \\
41-50 years Vs. $<20$ years & $1.52(0.86,2.71)$ & 0.000 \\
$>50$ years Vs. $<20$ years & $2.23(1.14,4.35)$ & \\
Weight status & & \\
Underweight Vs. Normal weight & $0.88(0.62,1.26)$ & \\
Overweight Vs. Normal weigh & $1.34(1.05,1.73)$ & 0.077 \\
$\quad$ Obese Vs. Normal weight & $1.92(1.38,2.67)$ & 0.051 \\
Level of education & & \\
Linear term & $19.85(0.72,546.16)$ & \\
Quadric term & $0.34(0.12,1.00)$ & \\
\hline$n=1688$ & &
\end{tabular}

compared to the normal and underweight males (Fig. 1). The likelihood of being hypertensive was 34.5\% (OR: 1.34; 95\% CI: 1.05, 1.73) and 92.1\% (OR: 1.92; 95\% CI: 1.38, 2.67) higher for overweight and obese males, respectively, compared to normal weight males (Table 5).

Table 6 Prevalence $(95 \% \mathrm{Cl})$ of unidentified hypertension among males by age, ethnicity, education level, body mass index category and waist circumference level

\begin{tabular}{ll}
\hline Variable & Hypertension \% (Cl) \\
\hline Age category & \\
$<20$ years & $24.5(20.5,28.9)$ \\
$20-30$ years & $28.2(25.1,31.4)$ \\
$31-40$ years & $31.8(28.4,35.3)$ \\
$41-50$ years & $40.1(35.3,45.0)$ \\
$>50$ years & $49.6(41.3,59.3)$ \\
Ethnicity & \\
Sinhalese & $31.7(29.7,33.8)$ \\
Tamil & $29.3(23.0,35.9)$ \\
Moor & $32.3(25.9,38.8)$ \\
Education level & \\
No education - grade 5 & $35.3(17.6,59.9)$ \\
Grade 6 - grade 11 & $32.6(27.8,37.7)$ \\
Ordinary level passed & $32.2(29.6,34.9)$ \\
Advanced level passed & $28.5(25.1,31.9)$ \\
Graduate/postgraduate & $48.4(37.5,61.9)$ \\
Weight status & \\
Normal weight & $27.0(24.3,29.9)$ \\
Underweight & $23.4(19.2,27.6)$ \\
Overweight & $36.5(33.1,40.0)$ \\
Obese & $44.9(39.3,50.8)$ \\
\hline$n=2462$ &
\end{tabular}

$n=2462$
Among different ethnic groups, Moors showed the highest undiagnosed hypertension prevalence rate $(32.3 \%)$ while Tamils exhibited the lowest (29.3\%). Also, the highest prevalence rate of undiagnosed hypertension was observed in individuals with the highest education level (Table 6).

\section{Discussion}

The aim of the current study was to identify the prevalence rate of undiagnosed HT and factors associated with it in a cohort of males in the Central Province of Sri Lanka. Of the 2462 males studied, 31.7\% had undiagnosed HT highlighting the large number of undiagnosed HT likely to be present in this region. Of the studied factors, age and obesity were significantly associated with HT, while level of education showed a trend of association.

In the current study, we excluded subjects who were previously diagnosed with hypertension to eliminate the confounding effects of lifestyle modification following the diagnosis of a non-communicable disease. As a result, all the subjects found to have HT in this study were previously undiagnosed ones. The HT prevalence rate of $31.7 \%$ is a higher value compared to previous studies done in Sri Lankan males. A study by Wijewardene et al. during 2000/2001 in four provinces of Sri Lanka showed a mean SBP of 120.1 (SD 20.4) $\mathrm{mm} \mathrm{Hg}$ and DBP of 75.4 (SD 11.7) $\mathrm{mm} \mathrm{Hg}$, with a crude prevalence rate for hypertension ( $\geq 140 / 90 \mathrm{mmHg}$ ) of $19.4 \%$ in males [19]. Mean SBP value of $129.0 \pm 19.4 \mathrm{mmHg}$ and DBP value of $75.2 \pm 11.6 \mathrm{mmHg}$ for males were reported by Katulanda et al., (2014), in the only national study that has been carried out in Sri Lanka in 2005/ 2006 [8]. The latter study further reported that the age adjusted prevalence of hypertension was $23.4 \%$ among males [8]. Therefore, it is possible that the prevalence of HT in Sri Lanka is on the rise, similar to world trends [1]. Comparatively, in the western Indian population, the overall prevalence of undiagnosed hypertension in 2013 was $26 \%$ [20] while it was $36.5 \%$ in males and $22.1 \%$ in females in USA in 1988-1994 [21]. Taken together, ours and many other studies have highlighted that undiagnosed hypertension is a serious issue which needs to be taken into consideration to overcome the morbidity and mortality associated with hypertension [22-24].

When considering the current study and other previous studies, it is clear that the prevalence rates of hypertension have been increasing over time. One possible reason could be the noticeable increase in obesity and average body mass index in Sri Lankans over the past decades [25], which in turn increased the prevalence of hypertension [26]. Similar trends have been observed in India and China [27, 28]. Further, Danaei, et al. have shown that between 1980 and 2008, SBP has increased 
A

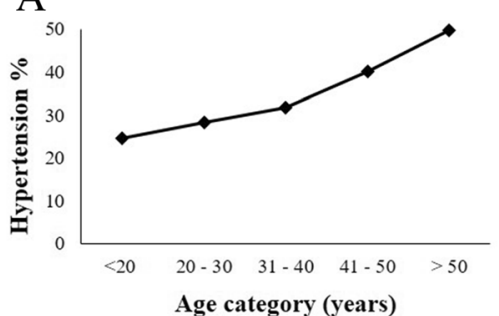

$\mathrm{C}$

$\mathrm{C}$

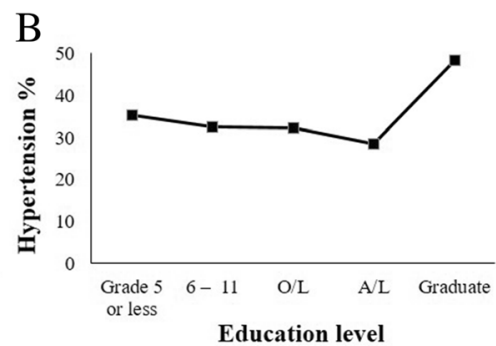

Education level

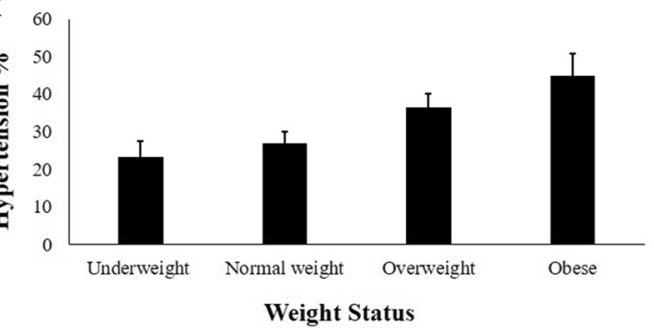

Fig. 1 Prevalence of hypertension by age, education level and weight status. Prevalence rates of undiagnosed hypertension (systolic blood pressure $\geq 140 \mathrm{mmHg}$ or diastolic blood pressure $\geq 90 \mathrm{mmHg}$ ) according to age categories (a), educational status (b) and weight status (c) are shown. $n=2462$

0.8-1.6 $\mathrm{mmHg}$ per decade in men and $1.0-2.7 \mathrm{mmHg}$ per decade in women in the South Asian region [29].

The current study shows that increasing age and BMI are significantly associated with HT. We also found trends for level of education to be associated with HT. Previously, Katulanda et al. found that male gender, physical inactivity, diabetes, central obesity and Moor ethnicity were significantly associated with hypertension among Sri Lankans, while no previous studies have looked at dietary patterns in detail [8]. Our data show that until 40 years of age, the odds of being hypertensive is more or less same and the likelihood increases after 40 years. Similar results have also been observed by Shukla, et al. where the prevalence of undiagnosed hypertension in western Indian population was approximately three times higher in the older population ( $>40$ years) than in younger adults [20]. Moreover, many research studies have reported aging as a major risk factor for becoming hypertensive [30, 31]. Mechanistically, the age related risk of HT is attributed to changes in vasculature which includes endothelial dysfunction, thickening of vessel walls, reduced flexibility and arterial stiffening [32].

Obesity is another well-known risk factor for HT [33]. The current study showed that weight, BMI and WC all positively correlated with SBP and DBP. Moreover, the weight status (BMI category) was independently associated with HT in the logistic regression analysis. Further, undiagnosed hypertension was highest among overweight and obese males compared to the normal and underweight males. The likelihood of being hypertensive was $34.5 \%$ (OR: 1.34; 95\% CI: 1.05, 1.73) and 92.1\% (OR: 1.92; 95\% CI: 1.38, 2.67) higher for overweight and obese males, respectively, compared to normal weight males. There are several mechanisms underlying the relationship between obesity and HT $[33,34]$. One mechanism could be that leptin, an adipokine found in higher levels in obese individuals, acts in the hypothalamus to increase blood pressure through activation of the sympathetic nervous system [34]. We have previously reviewed the role of systemic and adipose tissue renin-angiotensin systems in obesity-related HT $[35,36]$.

In the current study, level of education was trending towards significance $(p=0.058)$ when it was entered into the model as a categorical variable. According to our findings, HT was high among males who were least educated and the prevalence reduced with the increment of the level of education. Males who had advanced level education (Grade 11-13) showed lowest prevalence. However, when the educational level increased to the top (graduates/postgraduates), the level of HT again increased (Fig. 6). Previous studies have yielded contrasting results on the relationship between educational status and HT. Linear, significant negative associations were reported in some $[37,38]$, while others have indicated a higher prevalence of HT among the highest educated groups [39].

Fruit and vegetable consumption has a protective effect against hypertension. Alonso et al. showed that consumption of vegetables and fruits has an inverse linear relationship (77\% reduction) with the prevalence of undiagnosed hypertension [40]. According to our study, only $14.5 \%$ of the study group consumed one or more 
fruits per day [9]. This overall lower consumption of fruits could be a possible reason why the relationship between fruit intake and HT did not reach significance. Indeed, there are previous studies supporting the current finding of lower daily intake of fruits among Sri Lankans which is well below national recommendations [41]. Mechanistically, the high potassium content in fruits is suggested to lower the blood pressure thus exerting protective effects against HT [42]. Considering the possible relationship between lower fruit intake and the risk of $\mathrm{HT}$ as well as the low percentage of adult males meeting the recommended daily fruit intake, it is important to target promotion of fruit intake as an intervention to prevent HT in this area.

Alcohol is also another lifestyle factor which increases the risk of HT [43]. Indeed, some studies have attributed as much as $16 \%$ of all cases of HT to alcohol [44]. While $22.5 \%$ of the participants in the current study indicated that they were consuming alcohol, it might be an underestimate considering the stigma associated with alcohol intake in this region.

Physical inactivity has been shown to be associated with increased incidence of hypertension in many research studies conducted worldwide including Sri Lanka $[8,45,46]$. In contrast, our findings showed no association between physical activity and HT. It needs to be pointed out that the majority of this study group (64.5\%) reported that they engaged in more than $300 \mathrm{~min}$ of moderate-intensity physical activity per week. Since the self-reported physical activity levels were obtained, there is a possibility of over-reporting their physical activity levels. Indeed, it is well known that individuals over report physical activity levels [47]. This factor needs to be taken into account when interpreting the current finding of no association between physical activity level and HT in the current study.

Of the other factors considered in this study, we did not find an association between the number of sleep hours and HT. Previous studies have shown conflicting results regarding the association between sleep hours and blood pressure. Some have shown that short sleep duration is associated with HT [48], while others have shown that this association is only seen in women [49]. Since the current study group only comprised males, it is certainly warrented to further explore this relationship in Sri Lankans, especially in women.

While our cross-sectional study provided useful findings on the prevalence of undiagnosed hypertension and underlying risk factors among adult males of the Central province of Sri Lanka, there are some limitations. Since $>95 \%$ of the individuals who presented for this routine medical examination were males, we only included males for this study. Further, we could not investigate the relation between salt intake and HT.

\section{Conclusion}

The high prevalence rate of undiagnosed hypertension seen in working age males signifies a major health problem which requires urgent steps to be taken for its prevention and control. Routine screening is important to identify these undiagnosed individuals with HT, especially with advancing age. Since obesity was identified as a factor associated with HT, interventions targeted at reducing obesity rates are needed to curb the likely increases in cardiovascular morbidity and mortality of HT in this region.

\section{Abbreviations \\ BMI: Body mass index; Cl: Confidence interval; DBP: Diastolic blood pressure; HT: Hypertension; IPAQ: International physical activity questionnaire; SBP: Systolic blood pressure; SD: Standard deviation; WC: Waist circumference; WHO: World health organization \\ Acknowledgements \\ We acknowledge the Rajarata University of Sri Lanka, Mihinthale for funding the research. We also thank Ms. T.H. Lakshani Kawshalya, who assisted in data collection and all the staff members at the National Transport Medical Institute, Kandy, Sri Lanka for their tireless efforts in managing the participants and all the other individuals and institutions who helped in numerous ways for the research.}

\section{Funding}

This research was funded by the Rajarata University of Sri Lanka, Mihinthale, Sri Lanka (RJT/RP \& HDC/2013/Agric./PGR/02).

\section{Availability of data and materials}

The data analyzed in this paper can be made available to researchers. Requests for access to the dataset used in this paper should be directed to the corresponding author.

\section{Authors' contributions}

WATAJ, NSK, RSJ and UR made substantial contribution to conception and study design. SASBA and NWIAJ were involved in data collection. NWIAJ, WMTM, WATAJ, AMKRB and NSK were involved in refining the study design, statistical analysis and drafting the manuscript. All authors read and approved the final manuscript.

\section{Competing interests}

The authors declare that they have no competing interests.

\section{Ethics approval and consent to participate}

This study was approved by the ethics review committee (Institutional review board) of the Faculty of Medicine, University of Peradeniya, Sri Lanka (2015/EC/13). Informed written consent was obtained from all participants.

Consent for publication

Not applicable.

\section{Publisher's Note}

Springer Nature remains neutral with regard to jurisdictional claims in published maps and institutional affiliations.

\section{Author details}

${ }^{1}$ Department of Animal and Food Sciences, Faculty of Agriculture, Rajarata University of Sri Lanka, Anuradhapura, Sri Lanka. ${ }^{2}$ Department of Medicine, Faculty of Medicine, University of Peradeniya, Peradeniya, Sri Lanka. ${ }^{3}$ Department of Food Science and Technology, Faculty of Agriculture, University of Peradeniya, Peradeniya, Sri Lanka. ${ }^{4}$ National Transport Medical Institute, Kandy, Sri Lanka. ${ }^{5}$ Department of Agricultural Systems, Faculty of Agriculture, Rajarata University of Sri Lanka, Anuradhapura, Sri Lanka.

${ }^{6}$ Department of Physiology, Faculty of Medicine, University of Peradeniya, Peradeniya, Sri Lanka. 
Received: 14 March 2017 Accepted: 15 June 2017

Published online: 21 June 2017

\section{References}

1. Forouzanfar MH, Liu P, Roth GA, Ng M, Biryukov S, et al. Global burden of hypertension and systolic blood pressure of at least 110 to $115 \mathrm{~mm} \mathrm{hg}$, 1990-2015. JAMA. 2017;317(2):165-82

2. Murray CJ, Lopez AD. Global mortality, disability, and the contribution of risk factors: global burden of disease study. Lancet. 1997;349(9063):1436-42.

3. Lawes CM, Vander Hoorn S, Rodgers A. Global burden of blood-pressurerelated disease, 2001. Lancet. 2008:371(9623):1513-8.

4. Kearney PM, Whelton M, Reynolds K, Muntner P, Whelton PK, He J. Global burden of hypertension: analysis of worldwide data. Lancet. 2005;365(9455):217-23.

5. Ong KL, Cheung BM, Man YB, Lau CP, Lam KS. Prevalence, awareness, treatment, and control of hypertension among United States adults 1999-2004. Hypertension. 2007;49(1):69-75.

6. WHO. Noncommunicable diseases country profiles 2014. Geneva: 2014.

7. Tennakoon SU, Kumar BN, Nugegoda DB, Meyer HE. Comparison of cardiovascular risk factors between Sri Lankans living in Kandy and Oslo. BMC public health. 10(1):654

8. Katulanda P, Ranasinghe P, Jayawardena R, Constantine GR, Rezvi Sheriff M, Matthews DR. The prevalence, predictors and associations of hypertension in Sri Lanka: a cross-sectional population based national survey. Clin Exp Hypertens. 2014;36(7):484-91.

9. Jayawardana NW, Jayalath WA, Madhujith WM, Ralapanawa U, Jayasekera RS, Alagiyawanna SA, et al. Lifestyle factors associated with obesity in a cohort of males in the central province of Sri Lanka: a cross-sectional descriptive study. BMC Public Health. 2017;17(1):27.

10. Mancia G, De Backer, G., Dominiczak, A., Cifkova, R., Fagard, R., Germano, G., Grassi, G., Heagerty, A.M., Kjeldsen, S.E., Laurent, S. and Narkiewicz, K. 2007 guidelines for the management of arterial hypertension.. Eur Heart J 2007; 28(12):1462-1536.

11. WHO. Physical status: the use and interpretation of anthropometry. Report of a WHO Expert Committee. Geneva: World Health Organization: 1995.

12. Bassett J, Organization WH. The Asia-Pacific perspective: redefining obesity and its treatment: health communications Australia; 2000.

13. Koh JH, Koh SB, Lee MY, Jung PM, Kim BH, Shin JY, et al. Optimal waist circumference cutoff values for metabolic syndrome diagnostic criteria in a Korean rural population. J Korean Med Sci. 2010;25(5):734-7.

14. Booth ML, Ainsworth BE, Pratt M, Ekelund U, Yngve A, Sallis JF, et al. International physical activity questionnaire: 12-country reliability and validity. Med Sci Sports Exerc. 2003;195(9131/03):3508-1381

15. 2008 Physical Activity Guidelines for Americans. [database on the Internet] U.S. Department of Health and Human Services. 14. [cited 2015. 02.16] Available from: https://health.gov/PAGUIDELINES/pdf/paguide.pdf.

16. WHO. Global recommendations on physical activity for health. Geneva: World Health Organization, 2010.

17. Katulanda P, Ranasinghe P, Jayawardena R, Sheriff R, Matthews D. Metabolic syndrome among Sri Lankan adults: prevalence, patterns and correlates. Diabetol Metab Syndr. 2012;4(1):24.

18. Ko G, Chan J, Chan A, Wong P, Hui S, Tong S, et al. Association between sleeping hours, working hours and obesity in Hong Kong Chinese: the 'better health for better Hong Kong'health promotion campaign. Int J Obes. 2007:31(2):254-60

19. Wijewardene K, Mohideen M, Mendis S, Fernando D, Kulathilaka T, Weerasekara D, et al. Prevalence of hypertension, diabetes and obesity: baseline findings of a population based survey in four provinces in Sri Lanka. 2005.

20. Shukla AN, Madan T, Thakkar BM, Parmar MM, Shah KH. Prevalence and predictors of undiagnosed hypertension in an apparently healthy western Indian population. Advances in Epidemiology. 2015;2015

21. Ayanian JZ, Zaslavsky AM, Weissman JS, Schneider EC, Ginsburg JA. Undiagnosed hypertension and hypercholesterolemia among uninsured and insured adults in the third National Health and nutrition examination survey. Am J Public Health. 2003:93(12):2051-4

22. Johnson HM, Thorpe CT, Bartels CM, Schumacher JR, Palta M, Pandhi N, et al. Undiagnosed hypertension among young adults with regular primary care use. J Hypertens. 2014;32(1):65-74.

23. McDonald M, Hertz RP, Unger AN, Lustik MB. Prevalence, awareness, and management of hypertension, dyslipidemia, and diabetes among United
States adults aged 65 and older. J Gerontol Ser A Biol Med Sci. 2009;64(2): 256-63.

24. Hou X. Urban — rural disparity of overweight, hypertension, undiagnosed hypertension, and untreated hypertension in China. Asia Pac J Public Health. 2008;20(2):159-69.

25. Katulanda P, Jayawardena MAR, Sheriff MHR, Constantine GR, Matthews DR. Prevalence of overweight and obesity in Sri Lankan adults. Obes Rev. 2010; 11(11):751-6.

26. Hajjar I, Kotchen TA. Trends in prevalence, awareness, treatment, and control of hypertension in the United States, 1988-2000. JAMA. 2003;290(2):199-206.

27. Joshi SR, Saboo B, Vadivale M, Dani SI, Mithal A, Kaul U, et al. Prevalence of diagnosed and undiagnosed diabetes and hypertension in India-results from the screening India's twin epidemic (SITE) study. Diabetes Technol Ther. 2012;14(1):8-15.

28. Wu L, He Y, Jiang B, Sun D, Wang J, Liu M, et al. Trends in prevalence, awareness, treatment and control of hypertension during 2001-2010 in an urban elderly population of China. PLoS One. 2015;10(8):e0132814.

29. Danaei G, Finucane MM, Lin JK, Singh GM, Paciorek CJ, Cowan MJ, et al. National, regional, and global trends in systolic blood pressure since 1980: systematic analysis of health examination surveys and epidemiological studies with 786 country-years and 5. 4 million participants. Lancet. 2011; 377(9765):568-77.

30. Lloyd-Jones DM, Evans JC, Levy D. Hypertension in adults across the age spectrum: current outcomes and control in the community. JAMA. 2005; 294(4):466-72

31. Franklin SS, Gustin W, Wong ND, Larson MG, Weber MA, Kannel WB, et al. Hemodynamic patterns of age-related changes in blood pressure the Framingham heart study. Circulation. 1997;96(1):308-15.

32. Harvey A, Montezano AC, Lopes RA, Rios F, Touyz RM. Vascular fibrosis in aging and hypertension: molecular mechanisms and clinical implications. Can J Cardiol. 2016;32(5):659-68.

33. Landsberg L, Aronne L, Beilin LJ, Burke V, Igel LI, Lloyd-Jones D, et al. Obesity-related hypertension: pathogenesis, cardiovascular risk, and treatment: a position paper of the Obesity Society and the American Society of Hypertension. J Clin Hypertens (Greenwich). 2013;15(1):14-33.

34. Rahmouni K, Correia ML, Haynes WG, Mark AL. Obesity-associated hypertension new insights into mechanisms. Hypertension. 2005:45(1):9-14.

35. Kalupahana NS, Moustaid-Moussa N. The renin-angiotensin system: a link between obesity, inflammation and insulin resistance. Obes Rev. 2012;13(2):136-49.

36. Ramalingam L, Menikdiwela K, LeMieux M, Dufour JM, Kaur G, Kalupahana N, Moustaid-Moussa N. The renin angiotensin system, oxidative stress and mitochondrial function in obesity and insulin resistance. Biochim Biophys Acta. 2016 Aug 4. pii: S0925-4439(16)30187-9.

37. Tedesco MA, Di Salvo G, Caputo S, Natale F, Ratti G, larussi D, et al. Educational level and hypertension: how socioeconomic differences condition health care. J Hum Hypertens. 2001;15(10):727.

38. Wang Y, Chen J, Wang K, Edwards C. Education as an important risk factor for the prevalence of hypertension and elevated blood pressure in Chinese men and women. J Hum Hypertens. 2006;20(11):898.

39. Mendez MA, Cooper R, Wilks R, Luke A, Forrester T. Income, education, and blood pressure in adults in Jamaica, a middle-income developing country. Int J Epidemiol. 2003;32(3):400-8.

40. Alonso A, de la Fuente C, Martín-Arnau AM, de Irala J, Martínez JA, MartínezGonzález MÁ. Fruit and vegetable consumption is inversely associated with blood pressure in a Mediterranean population with a high vegetable-fat intake: the Seguimiento Universidad de Navarra (SUN) study. Br J Nutr. 2004; 92(02):311-9.

41. Jayawardena R, Byrne NM, Soares MJ, Katulanda P, Hills AP. Food consumption of Sri Lankan adults: an appraisal of serving characteristics. Public Health Nutr. 2013;16(04):653-8.

42. Lampe JW. Health effects of vegetables and fruit: assessing mechanisms of action in human experimental studies. Am J Clin Nutr. 1999;70(3 Suppl): 475S-90S.

43. Beilin LJ, Puddey IB. Alcohol and hypertension an update. Hypertension. 2006:47(6):1035-8

44. Rehm J, Room R, Monteiro M, Gmel G, Graham K, Rehn N, et al. Alcohol as a risk factor for global burden of disease. Eur Addict Res. 2003;9(4):157-64.

45. Haapanen N, Miilunpalo S, Vuori I, Oja P, Pasanen M. Association of leisure time physical activity with the risk of coronary heart disease, 
hypertension and diabetes in middle-aged men and women. Int $J$ Epidemiol. 1997;26(4):739-47.

46. Hu G, Barengo NC, Tuomilehto J, Lakka TA, Nissinen A, Jousilahti P. Relationship of physical activity and body mass index to the risk of hypertension: a prospective study in Finland. Hypertension. 2004;43(1):25-30.

47. Prince SA, Adamo KB, Hamel ME, Hardt J, Gorber SC, Tremblay M. A comparison of direct versus self-report measures for assessing physical activity in adults: a systematic review. Int I Behav Nutr Phys Act. 2008;5(1):56.

48. Gangwisch JE, Heymsfield SB, Boden-Albala B, Buijs RM, Kreier F, Pickering TG, et al. Short sleep duration as a risk factor for hypertension analyses of the first national health and nutrition examination survey. Hypertension. 2006;47(5):833-9.

49. Cappuccio FP, Stranges S, Kandala NB, Miller MA, Taggart FM, Kumari M, et al. Gender-specific associations of short sleep duration with prevalent and incident hypertension: the Whitehall II study. Hypertension. 2007:50(4):693-700.

Submit your next manuscript to BioMed Central and we will help you at every step:

- We accept pre-submission inquiries

- Our selector tool helps you to find the most relevant journal

- We provide round the clock customer support

- Convenient online submission

- Thorough peer review

- Inclusion in PubMed and all major indexing services

- Maximum visibility for your research

Submit your manuscript at www.biomedcentral.com/submit
C) Biomed Central 